\title{
3. Desenvolvimento do estudo: estratégia inicial ${ }^{1}$
}

\author{
Developing a study: initial strategy
}

\author{
Fabio Xerfan Nahas ${ }^{2}$, Bernardo Hochman ${ }^{3}$, Lydia Masako Ferreira ${ }^{4}$ \\ 1. Programa de Pós-Graduação em Cirurgia Plástica da Universidade Federal de São Paulo - Escola Paulista de Medicina (UNIFESP-EPM). \\ Disciplina de Cirurgia Plástica da UNIFESP-EPM. \\ 2. Professor Adjunto Visitante da Disciplina de Cirurgia Plástica da UNIFESP-EPM. Professor Orientador do Programa de Pós-Graduação \\ em Cirurgia Plástica da UNIFESP-EPM \\ 3. Mestre em Medicina e pós-graduando em nível de doutorado pelo Programa de Pós-Graduação em Cirurgia Plástica da UNIFESP - EPM. \\ 4. Professora Titular da Disciplina de Cirurgia Plástica da UNIFESP-EPM. Coordenadora do Programa de Pós-Graduação em Cirurgia \\ Plástica da UNIFESP-EPM
}

\begin{abstract}
RESUMO
Neste artigo são discutidas a elaboração do estudo e a redação do projeto. Os possíveis motivos que levam à rejeição de um artigo, como o foco do periódico, a redação do artigo e erros de gramática são considerados. São descritos os passos iniciais de um estudo científico como a escolha da idéia, o levantamento de artigos e a seleção dos trabalhos principais disponíveis na literatura. Após a discussão em grupos sobre o objetivo do estudo e seus métodos ("brainstorm”), o projeto é desenvolvido e seus itens (Introdução, Objetivo, Métodos, Protocolo, Referências e Cronograma) são analisados.
\end{abstract}

Descritores: Artigo de Revista, Redação, Editoração

\begin{abstract}
In this article the preparation of a scientific paper and its project are described. The possible reasons that lead to rejection of an article such as the proper focus of the chosen journal, its writing and mistakes in the grammar are considered. The initial steps of a scientific paper such as the choice of an idea, literature search, and the selection of related articles are described. After a group discussion about the purpose of the paper and its methods (brainstorm), the project is described and its items (Introduction, Objective, Methods, Protocol, References and Chronogram) are analyzed.
\end{abstract}

Key words: Journal Article, Writing, Publishing

Pesquisas científicas devem ser divulgadas para possibilitar o avanço da ciência. Estes estudos podem ser apresentados em encontros científicos, ou publicados em livros ou periódicos. Mais recentemente, a internet passou a ser outra opção de divulgação destas pesquisas. A apresentação de trabalhos científicos em congressos tem, como vantagem, a troca de idéias entre estudiosos de um mesmo assunto. Entretanto, o material escrito, embora não seja eterno, é mais duradouro do que a palavra falada. Estima-se que a vida científica de um livro varia de 1 a 2 anos, enquanto que um artigo escrito em um periódico tem 10 anos de durabilidade científica. Nos Estados Unidos, o peso acadêmico de um capítulo de livro é 0,1 enquanto o peso de um artigo publicado em revista de primeira linha é de 1, na seleção de professores universitários. O peso da autoria de um livro inteiro é de 1 a 2, dependendo de sua importância ${ }^{1}$. Desta forma, assuntos novos devem ser preferencialmente publicados em periódicos. Publicar artigos em periódicos nem sempre é uma tarefa fácil. Existem alguns problemas que levam um artigo a ser rejeitado. O mais óbvio fator de rejeição é quando o estudo foi mal elaborado ou conduzido. Geralmente estes erros de elaboração ocorrem por informação insuficiente ou inadequada, amostra viciada, parâmetros confusos, hipóteses e objetivos sem clareza. Entretanto, existem outros dois tipos comuns de erros que, por vezes não são facilmente observados pelos autores. A escolha errada do periódico é um destes fatores. Todo periódico descreve seus objetivos, geralmente na página sobre instruções para autores. É o chamado foco da revista, que deve ser respeitado sob a pena de o artigo ser rejeitado. Um periódico cujo foco é estudo experimental em cirurgia plástica, não irá aceitar para publicação artigos de casos clínicos, por melhores que sejam. O outro fator de rejeição é a redação. Artigos mal escritos, por erros de gramática ou estilo podem ser rejeitados. Devese dar atenção especial a artigos escritos em língua estrangeira onde este tipo de erro é mais comum. Neste artigo serão discutidas a elaboração do estudo e a redação do projeto. 


\section{Elaboração do estudo}

A elaboração de um trabalho científico é iniciada pela escolha do tema a ser estudado. A seleção do assunto é importantíssima e refletirá na viabilidade da realização do trabalho proposto e em sua importância para a ciência ${ }^{2}$. Todo trabalho científico deve partir de uma pergunta que, de preferência ainda não tenha uma resposta na literatura médica. Um ponto de partida pode ser os próprios artigos sobre o assunto selecionado, encontrados ao se estudar o assunto. Todos os artigos deixam algumas questões não resolvidas e que podem originar novos estudos. Após a definição do assunto, elabora-se uma idéia de qual aspecto será estudado. Inicia-se a busca na literatura mundial através das bases de dados, Medline (Index Médico), Exerpta Médica (origem européia), Current Contents, LILACS (latinoamericano). São procuradas pesquisas na mesma linha ou até estudos iguais. Se forem encontrados estudos semelhantes, deve-se ponderar sobre o significado de se realizar o estudo proposto. Uma repetição do que já está comprovado pode invalidar o trabalho. Entretanto, estudos podem ser repetidos com métodos diferentes e ter resultados diferentes das pesquisas encontradas na literatura. Além disso, a confirmação de estudos anteriores, com diferentes métodos, pode ser de vital importância científica. A revisão sistemática da literatura, através de diversos bancos de dados, pode, por si só, já oferecer uma resposta para aquela pergunta e merecer uma publicação. Neste momento o pesquisador deverá utilizar uma ficha por artigo estudado ${ }^{3,4}$. Nesta ficha deverá constar a identificação do artigo e um resumo sintético do artigo. Este tipo de resumo servirá como uma identificação rápida da idéia principal do estudo e será utilizado novamente quando as idéias forem colocadas no papel. Após a leitura do material bibliográfico, deve-se refletir sobre o tema fazendo um "brainstorm" sobre o assunto 5 . São levantadas questões sobre o assunto, críticas sobre o método e material utilizados e possíveis variações que poderiam facilitar a realização do trabalho. É ideal que este tipo de reflexão seja realizada em grupo, preferencialmente com colegas que tenham alguma afinidade com a área escolhida. Procura-se, entretanto, deixar o pensamento fluir livremente para evitar a inibição de novas idéias por críticas.

\section{Realização do projeto}

O próximo passo é escrever um projeto. O projeto é uma maneira sintética de se organizar todos os dados a serem obtidos para a confecção do trabalho. Deve-se prever todos os dados de possível necessidade para o estudo, pois é melhor sobrar dados do que faltar. O pesquisador deve esforçar-se e dedicar tempo neste item. A confecção de um projeto ruim pode ter conseqüências negativas ou até inviabilizar o trabalho ${ }^{6}$. Se o trabalho tiver um orientador, o estudo deve ser apresentado, já nesta fase, da seguinte forma:

\author{
I - Introdução (e objetivo) \\ II - Métodos \\ III - Protocolo \\ IV - Referências \\ V - Cronograma
}

A Introdução deve situar o leitor em relação ao tema e mostrar a relevância do estudo em questão. A introdução do projeto poderá ser mais extensa que a do artigo, pois neste momento o autor poderá explicar o porquê vale a pena realizar o estudo. No final da introdução o objetivo deverá estar claramente colocado. É a pergunta a qual se pretende responder com o trabalho. O método divide-se em descrição da amostra e descrição do procedimento. A amostra (n) é um grupo selecionado que deve ser representativo de um universo. A seleção da amostra deve obedecer a critérios de inclusão e exclusão, os quais devem ser definidos já nesta fase. O tamanho da amostra deve ser estimado conjuntamente com o estaticista que irá basear-se no desvio padrão. Na descrição do procedimento é de extrema importância que este possa ser reproduzível. Neste ponto, o estudo deve ser avaliado por uma comissão de ética. Hoje, no Brasil, existe a exigência de que qualquer estudo clínico, experimental ou anatômico seja submetido e avaliado por uma comissão de ética da instituição. Um plano piloto pode ser de grande valia para auxiliar na determinação do número de casos a serem estudados, assim como para verificar se o método é factível. O protocolo é onde os dados colhidos são escritos. Um bom protocolo deve prever todos os dados necessários ao estudo. O protocolo deve ser objetivo, resumido e completo. Se houver dúvida sobre a utilização de algum dado, o mesmo deve ser obtido e, se não for utilizado poderá ser descartado. O cronograma deve ser colocado na forma de tabela. Deve ser lógico e factível. Pode ser organizado a partir da experiência com o plano piloto no qual o tempo de realização do procedimento já foi determinado. Após discussão com o orientador, o estudo é realizado e os dados são colhidos. Estes dados serão analisados estatisticamente (quando for necessário) e o trabalho será passado ao papel. Com estes valores em mãos, o pesquisador irá escrever os itens Resultados, Discussão e Conclusão.

\section{Referências}

1. Buckingham TA. How to write medical and scientific papers. [updated 2004 Oct 16; cited 2004 Nov 12]. Available from: http://www.lifescipub.com/ebook.htm.

2. Gonçalves EL. O processo mental, a elaboração do pensamento científico e a operacionalização da pesquisa. In:Gonçalves EL, editor. Pesquisa médica. 1st. ed. São Paulo: EPU- Conselho Nacional de Desenvolvimento Científico e Tecnológico; 1983.p.124-108.

3. Eco U. Como se faz uma tese. 15th. ed. São Paulo: Perspectiva; 2000.

4. Severino AJ. Metodologia do trabalho científico. 20th. ed. São Paulo:Cortez Editora;1996. 
5. Carmo-Neto D. Metodologia científica para principiantes. 3rd. ed. Salvador:American World University Press; 1996.
6. Nahas FX, Ferreira LM, Sabino Neto M, Garcia EB. Elaboração de trabalho científico. Rev Bras Cir Plast. 2004 19(2):11-28.

\section{Correspondência:}

Fabio Xerfan Nahas

Disciplina de Cirurgia Plástica / Departamento de Cirurgia

Universidade Federal de São Paulo (UNIFESP - EPM)

Rua Napoleão de Barros, 715 - $4^{\circ}$ andar

04024-900 São Paulo - SP Brasil

Tel: (5511) 5576-4118

nahas.dcir@epm.br

\section{Como citar este artigo:}

Nahas FX, Hochman B, Ferreira LM. Desenvolvimento do estudo - estratégia inicial. Acta Cir Bras [periódico na Internet] 2005;20 Suppl. 2:10-2. Disponível em URL: http://www.scielo.br/acb 